\title{
Neurophysiological study of the effect of combined kidney and pancreas transplantation on diabetic neuropathy: a 2-year follow-up evaluation
}

\author{
G. Comi ${ }^{1}$, G. Galardi ${ }^{1}$, S. Amadio ${ }^{1}$, E. Bianchi ${ }^{1}$, A. Secchi ${ }^{2}$, S. Martinenghi ${ }^{2}$, R. Caldara ${ }^{2}$, G. Pozza ${ }^{2}$ and \\ N. Canal ${ }^{1}$ \\ Departments of ${ }^{1}$ Neurology and ${ }^{2}$ Internal Medicine, Istituto Scientifico San Raffaele, Milan, Italy
}

\begin{abstract}
Summary. Previous study have reported a significant improvement of peripheral neuropathy following combined pancreas and kidney transplantation attributed to improvement of blood glucose control by some authors and to elimination of uraemia by others. To asses the specific role of uraemia and hyperglycaemia in neuropathy, 16 diabetic uraemic patients with combined pancreas and kidney transplantation were compared to 9 diabetic patients with a renal graft only. Neurophysiological studies of peripheral neuropathy included ulnar and deep peroneal nerve motor conduction velocity, median and sural nerve sensory conduction velocity were performed at baseline and 1 and 2 years after transplantation. One year after transplantation mean nerve conduction velocity significantly improved in both groups. However, changes were statistically significant in the kidneypancreas group only. At the 2 year follow-up nerve conduction velocity had increased further in the pancreaskidney group only. These data suggest that improvement of nerve conduction velocity following pancreas and kidney transplantation is predominantly due to the long-term euglycaemic state.
\end{abstract}

Key Words: Pancreas transplantation - Kidney transplantation - Diabetic neuropathy.

\section{Introduction}

In spite of important recent advances in experimental and clinical studies, the cause of diabetic neuropathy is still unknown. Vascular, metabolic, neurotrophic and immunological mechanisms have been proposed (Thomas 1990) but none of the pathogenic hypotheses can explain the wide range of peripheral nerve abnormalities observed in patients with diabetes mellitus. Hyperglycaemia is a salient manifestation of diabetes: the possible correlation between hyperglycaemia and peripheral neuropathy therefore constitutes a major problem.

In rats with experimental diabetes early correction of hyperglycaemia by insulin therapy prevents the slowing of nerve conduction; however, the reduced nerve conduction velocity in animal models cannot be considered a good model of human diabetic neuropaihy. These early changes observed in experimental diabetes are probably similar to the acute changes of nerve conduction velocity observed in diabetic patients at onset of the disease (Ward 1971). These abnornormalities are rapidly reversible with the correction of hyperglycaemia and they do not relate to the future development of peripheral neuropathy (Comi 1986).

In patients with established peripheral neuropathy both nerve conduction velocity and vibration sense have been reported as improving under strict metabolic control (Boulton 1981; Service 1985).

Successful pancreas transplantation determines a normoglycemic state as long as the graft remains functional. If hyperglycaemia is a causal factor of diabetic peripheral neuropathy an improvement of nerve function shold be seen after successful pancreas graft. Results of previous studies seem to confirm an improvement in diabetic peripheral neuropathy after pancreas transplantation (Van Der Vliet 1988; Landgraf 1986; Secchi 1990). Uraemia seems to play a minor role comapared to diabetes in the aetiology of neuropathy (Van Der Vliet 1988; Mitz 1984). Nevertheless, in a recent study (Solders 1987) it has been suggested that the improvement in nerve conduction after combined pancreas and kidney transplantation was probably due to the elimination of uraemia.

Below we will present neurological follow-up data in 16 Type I diabetic patients with well functioning combined pancreas and kidney transplantation. These 
patients were compared with 9 diabetic patients receiving a kidney graft only.

\section{Subjects and methods}

Sixteen Type I diabetic patients (group KP), 9 male and 7 female, who retained a functioning combined kidney and pancreas transplant were examined prior to and 1 year after transplantation. Among them, twelve patients had a follow-up of two years. The mean age of the patients at the time of transplant was 38.1 years (SD 7.2); mean duration of the disease was 25.1 years (SD 6.2) and the mean duration of dialisys was 19.9 months (SD15.9). Patient management has been described in full elsewhere (Pozza 1991).

The control group consisted of 9 Type I diabetic patients with a functioning kidney graft (K group): 4 males and 5 females. The mean age of this group was 38.8 years (SD 7.3); the mean duration of diabetes was $23.1 \mathrm{yrs}$ (SD 4.0) and the mean duration of dialisys before transplantation 19 months (SD 14.5). This group of patients was examined before and 1 year after transplantation; 6 out of 9 patients were also examined at 2-year follow-up

Patient Evaluation. Nerve conduction studies were performed at a constant cutaneous temperature of $33{ }^{\circ} \mathrm{C}$, under automatic control with a DISA type $15 \mathrm{H} 02$ temperature regulator system.

Motor nerve conduction velocity (MCV) was measured in the right ulnar and deep peroneal nerve. The amplitude of the evoked muscle action potential (MAP) was recorded from the hypothenar and digitorum brevis muscles, respectively.

The antidromic sensory nerve conduction velocity (SCV) was measured in the median nerve (elbow-wrist and wrist-forefinger tracts) and in the sural nerve (calf-ankle tract). The sensory action potential (SAP) was also measured. When an evoked motor or sensory response was not obtained after nerve stimulation the values of the parameters were considered as missing values.

The degree of alteration of motor and sensory nerve conduction velocity in each patient was expressed as an index (NCV index). It was calculated by adding the deviation, expressed in $\mathrm{SD}$, of each of the 5 nerve conduction velocity values from normal age-matched laboratory subjects and dividing the sum of these deviations by 5 . Severity of symptoms of autonomic and peripheral neuropathy were measured with a conventional score.

Statistical analysis. The paired Student t-test was used in the statistical analysis of the clinical and electrophysiological data.

\section{Results}

Insulin was discontinued within the first weeks after surgery in all the patients receiving a combined kidney and pancreas transplant. Mean levels of glycosylated haemoglobin and serum creatinine 1 and 2 years after transplantation in the two groups of patients are reported in Table 1.

Table.1

Metabolic data

\begin{tabular}{lll}
\hline & KP & $K$ \\
\hline $\mathrm{n}$ & 12 & 6 \\
\hline HbA1C\%a & & \\
baseline & $6.6 \pm 1.7$ & $7.2 \pm 1.1$ \\
1 year & $5.9 \pm 0.7$ & $7.2 \pm 0.6$ \\
2 year & $5.9 \pm 1.1$ & $7.2 \pm 1.1$ \\
a values are mean \pm SD. Normal values $=3.5-6 \%$ \\
KP= simulatneous kidney and pancreas transplantation \\
K= Kidney transplantation alone
\end{tabular}

Before transplantation all patients in both groups showed symptoms and/or signs of peripheral neuropathy and alterations of two or more nerve conduction parameters.

Symptoms of autonomic neuropathy were mentioned by 10 patients of the group with combined kidney and pancreas transplantation and by 6 patients with kidney transplantation only.

One year after transplantation the mean variation of the peripheral neuropathy symptom score was - 3.2 ( SEM 0.8) in patients with combined transplantation and - 2.0 (SEM 1.1) in patients with kidney transplantation only; the difference between groups was not significant.

One year after transplantation symptoms of autonomic neuropathy improved in patients with combined transplantation (mean score - 1.6 SEM 0.6) but not in patients with kidney transplantation only (mean score + 0.1 SEM 0.3); the difference between groups was statistically significant $(\mathrm{p}<0.01)$.

Before transplantation the mean values of $\mathrm{NCV}$ and MAP and SAP amplitude were below the normal range. At 1 year after transplantation the mean $\mathrm{MCV}$ and SCV of all nerves significantly improved in both groups, however changes were statistically significant in the KP group only ( Table 2). The mean MAP and SAP amplitudes increased slightly in both groups: changes were not statistically significant.

Table 2

Nerve conduction velocity values in diabetic patients before and at 1 year after simultaneous kidney and pancreas transplantation (KP 16 patients) and kidney transplantation alone ( $\mathrm{K} 9$ patients)

\begin{tabular}{llll}
\hline $\begin{array}{l}\text { baseline } \\
\mathrm{m} / \mathrm{sec}\end{array}$ SD & $\begin{array}{l}1 \text { year } \\
\mathrm{m} / \mathrm{sec}\end{array}$ & SD \\
\hline
\end{tabular}

$\begin{array}{lllllll}\begin{array}{l}\text { Sural nerve } \\ \text { SCV }\end{array} & & & & & \\ & \text { KP } & \mathbf{3 6 . 0} & \mathbf{3 . 3} & \mathbf{4 0 . 5} & 4.7 & \text { a } \\ \text { K } & \mathbf{3 8 . 4} & \mathbf{3 . 2} & \mathbf{4 0 . 0} & \mathbf{4 . 6} & \text { ns }\end{array}$

Median nerve $\operatorname{SCV}(\mathbf{w} \cdot f)$

$\begin{array}{llllll}\text { KP } & 39.1 & 5.8 & 44.7 & 4.7 & \text { b } \\ \text { K } & 43.6 & 4.3 & 46.2 & 6.7 & \text { ns }\end{array}$

Median nerve $\operatorname{SCV}(\mathrm{e}-\mathrm{w})$

$\begin{array}{llllll}\text { KP } & 48.7 & 3.6 & 54.9 & 4.7 & \text { b } \\ \text { K } & \mathbf{5 2 . 0} & \mathbf{2 . 6} & \mathbf{5 5 . 9} & \mathbf{5 . 3} & \text { ns }\end{array}$

Peroneal nerve MCV

$\begin{array}{llllll}\text { KP } & 33.2 & 6.5 & 37.8 & 8.1 & \text { a } \\ \text { K } & 37.0 & 4.3 & 39.1 & 3.1 & \text { ns }\end{array}$

Ulnar nerve

MCV

$\begin{array}{llllll}\text { KP } & 48.1 & 4.4 & 51.8 & 5.1 & \text { a } \\ \text { K } & 49.3 & 2.9 & 50.4 & 2.3 & \text { ns }\end{array}$

Values are mean $+\mathrm{SD} . \mathrm{SCV}=$ sensory conduction velocity; $\mathrm{MCV}=$ motor conduction velocity; $\mathrm{w}-\mathrm{f}=$ wrist-finger; $\mathrm{e}-\mathrm{w}=$ elbow-wrist; paired t-test: $\mathrm{a}=\mathrm{vs}$ basal (a $\mathrm{p}<0.05 ; \mathrm{b} \mathrm{p}<0.01$ ) 
At 2 years after combined transplantation there was a further increase in mean $\mathrm{MCV}$ and SCV of all examined nerves: changes were significant for sural nerve SCV and median nerve SCV in the elbow-wrist tract (Table 3 ). In the $\mathrm{K}$ group mean nerve conduction values were unmodified.

Table. 3

Nerve conduction values in diabetic patients before and at 1 and 2 years after simulatneous kidney and pancreas transplantation (KP 12 pts) and kidney transplantation alone (K 6 pts)

\begin{tabular}{|c|c|c|c|c|c|}
\hline & $\begin{array}{l}\text { baseline } \\
\mathrm{m} / \mathrm{sec}\end{array}$ & SD & $\begin{array}{l}\text { 1year } \\
\mathrm{m} / \mathrm{sec}\end{array}$ & SD & $\begin{array}{l}\text { 2years } \\
\mathrm{m} / \mathrm{sec} \text { SD }\end{array}$ \\
\hline \multicolumn{6}{|l|}{$\begin{array}{l}\text { Sural Nerve } \\
\text { SCV }\end{array}$} \\
\hline $\mathbf{K P}$ & 36.4 & $\mathbf{3 . 0}$ & $40.1^{a}$ & 3.2 & $41.5^{\mathrm{a}} 3.0$ \\
\hline $\mathrm{K}$ & 37.1 & 5.2 & 36.3 & 1.9 & $38.7^{c} 2.0$ \\
\hline \multicolumn{6}{|l|}{$\begin{array}{l}\text { Median N } \\
\text { SCV (w-f) }\end{array}$} \\
\hline $\mathbf{K P}$ & 39.2 & 6.4 & $44.0^{\mathrm{a}}$ & 5.3 & $45.8^{\mathrm{b}} 8.4$ \\
\hline $\mathbf{K}$ & 43.2 & 2.9 & $45.7^{\mathrm{a}}$ & 2.7 & $47.9 \quad 4.3$ \\
\hline \multicolumn{6}{|l|}{$\begin{array}{l}\text { Median N } \\
\text { SCV (e-f) }\end{array}$} \\
\hline $\mathbf{K P}$ & 48.2 & 4.0 & $54.7^{b}$ & 5.2 & $57.5^{b, c} 2.7$ \\
\hline $\mathbf{K}$ & 51.6 & 1.5 & 56.2 & 4.5 & $55.7^{\mathrm{a}} \quad 1.9$ \\
\hline \multicolumn{6}{|l|}{$\begin{array}{l}\text { Peroneal N } \\
\text { MCV }\end{array}$} \\
\hline $\mathbf{K P}$ & 31.9 & 7.2 & 35.6 & 7.2 & $37.1^{\mathrm{a}} 6.0$ \\
\hline $\mathbf{K}$ & 36.7 & 5.1 & 38.3 & 4.5 & $38.4 \quad 4.1$ \\
\hline \multicolumn{6}{|l|}{$\begin{array}{l}\text { Ulnar N } \\
\text { MCV }\end{array}$} \\
\hline KP & 48.5 & 4.6 & 51.9 & 5.1 & $52.5^{\mathrm{a}} 4.4$ \\
\hline $\mathbf{K}$ & 49.2 & 3.7 & 49.6 & 3.0 & $50.6 \quad 3.0$ \\
\hline
\end{tabular}

Values are mean $\pm \mathrm{SD} . \mathrm{SCV}=$ sensory conduction velocity; $\mathrm{MCV}=$ motor conduction velocity; $w-f=$ wrist-finger; $e-w=$ elbow-wrist; paired t-test: $a=$ vs basal $(\mathrm{p}<0.05 ; \mathrm{b} p<0.01)$; $\mathrm{c}=$ vs 1 year $(\mathrm{p}<0.05)$.

NCV index before transplantation was significantly lower in the KP group compared with the K group; the difference between the two groups was reduced 1 year after transplantation and non-existent 2 years after transplantation (Fig. 1). Both groups showed a significant improvement in NCV index at 1 year after transplantation; the improvement continued in the $\mathrm{KP}$ group but not in the $\mathrm{K}$ group at 2 years (Fig. 2).
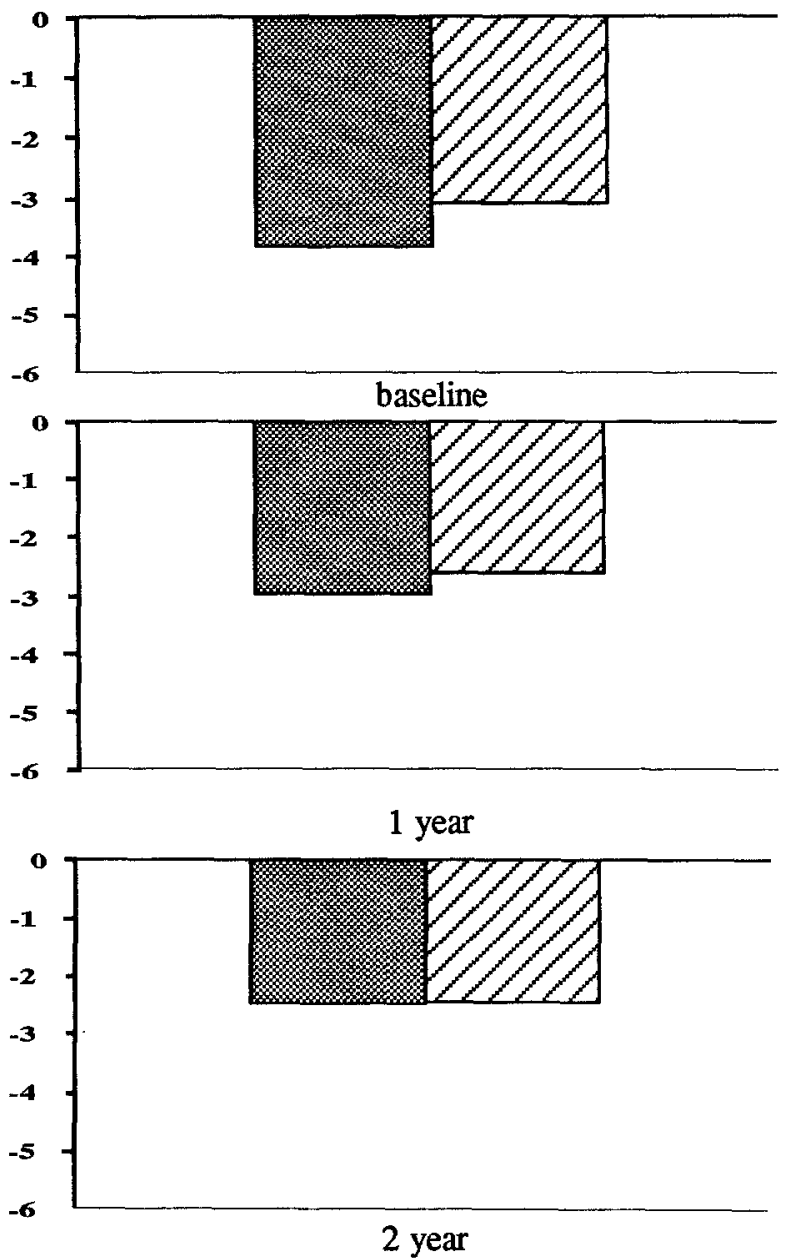

Fig.1

Nerve conduction velocity index in Type 1 (insulin-dependent) diabetic uraemic patients after simultaneous pancreas and kidney ( 51 nerves) or kidney ( ש 28 nerves) transplantation. Upper panel values before transplantation $(\mathrm{p}=0.05)$; medium panel values 1 year after transplantation ( $p=n s)$; lower panel values 2 years after transplantation $(\mathrm{p}=\mathrm{ns})$

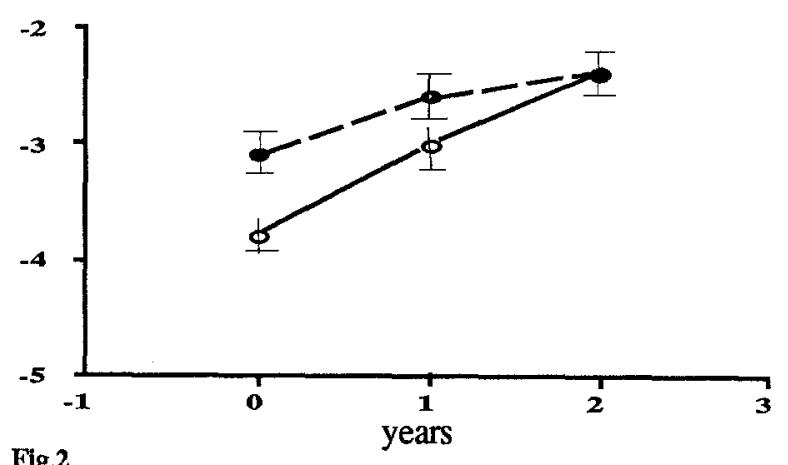

Fig.2

Improvement in nerve conduction velocity index in Type 1 (insulindependent) uraemic patients after simultaneous pancreas and kidney transplantation ( $O \quad$ KP: 51 nerves) or kidney transplantation ( K: 28 nerves) 1 and 2 years after surgery (KP basal vs 1 year: $p<0.001,1$ year vs 2 years: $p<0.001 ; K$ basal vs 1 year: $\mathrm{p}<0.01,1$ year vs 2 years: $\mathrm{p}=\mathrm{ns}$ ) 


\section{Discussion}

In this neurophysiological prospective study during a 2 year follow-up period, diabetic patients with a successful combined kidney-pancreas transplantation were compared to diabetic patients with successful kidney transplantation to evaluate the effects on peripheral neuropathy. An improvement in nerve conduction parameters was evident in both groups. However, in patients with combined kidney and pancreas transplantation, nerve conduction velocity continued to increase during the second year of followup while in patients with kidney transplantation alone, nerve conduction velocity increased only in the first year after transplatation. Moreover, even during the first year after transplantation neurophysiological changes were more obvious in patients with combined kidney and pancreas transplantation. Our results differ partially from the results of Solders et al. (1987) who found the same improvement of peripheral neuropathy in diabetic patients who underwent simultaneous kidney and pancreatic transplantation and in diabetic patients who underwent kidney transplantation alone.

These authors concluded that the improvement in peripheral nerve function in patients with diabetic neuropathy after renal and pancreatic transplantation is due to the elimination of uraemia.

Our results suggest that the elimination of uraemia can contribute to improvement of the peripheral neuropathy only in the period immediately following the combined kidney and pancreas transplantation; nerve function subsequently continues to improve only as a consequence of a persistent normoglycaemic state.

Kennedy et al. (1990) published results very similar to ours: in patients who received pancreatic transplant followed-up for $\mathbf{4 2}$ months, motor and sensory indexes improved especially at the 12 -month examination. The improvement in peripheral nerve function was observed also in patients without kidney transplantation.

The minor importance of uraemia compared to diabetes in the aetiology of neuropathy in diabetic uraemic patients is also supported by the demostration by Van Der Vliet et al. (1988) that nerve conduction values remained unchanged for as long as 10 years after kidney transplantation. Patients examined by these authors had severe slowing of nerve conduction which could have halted the positive effects of the elimination of uraemia.

A certain role, even if minor, of uraemia in peripheral nerve dysfunction in diabetic uraemic patients is also suggested by the improvement in peripheral neuropathy in non-diabetic uraemic patients after renal transplantation (Nielsen 1974, Bolton 1976).

The clinical relevance of the observed changes of nerve conduction velocity following pancreas transplantation is unclear; symptoms of autonomic and peripheral neuropathy improved in our patients. Quantitative sensory tests and cardiovascular autonomic tests were performed in a few cases: these tests did not change appreciably as reported by others (Solders 1987, Kennedy 1990). As suggested by Kennedy et al. (1990) the subjective improvement in sensation and endurance could be due to the improvement in the quality of life and to the psychotropic effects of steroids.

What is relevant is that after pancreas transplantation we did not observe progression of peripheral neuropathy or acute episodes of neuropathy. Changes of nerve conduction velocity in diabetic neuropathy can simply reflect functional changes in nerve fibers, a phenomenon that is frequently observed at the onset of diabetic disease (Ward 1971). The only neurophysiological evidence of nerve fiber regeneration is an increase in the amplitude of motor and sensory action potentials: in our study, as in others (Solders 1987, Kennedy 1990) amplitude of the action potentials increased slightly and only in the upper extremity. These data suggest that nerve fiber regeneration could occur in less damaged nerves. Only long-term followup studies will clarify the exact role of pancreas transplantation in the treatment of diabetic neuropathy.

\section{References}

Bolton C (1976) Electrophysiological changes in diabetic neuropathy after sucessful renal transplantation. Neurology (Minnap) 26: 152-161

Boulton AJM, Clarke B, Drury J, Ward JD (1981) Comparison of symptomatic relief with biothesiometers measurements in diabetic neuropathy treated with subcutaneous insulin infusion. Diabetologia 21:505

Comi G, Canal N, Lozza L, Beccaria L, Meschi F, Vanini R, Flores D'Arcais A, Chiumello G (1986) Peripheral nerve abnormalities in newly-diagnosed diabetic children Acta Diabetol Lat 23: 69-75

Kennedy WR, Navarro $X$, Goetz FC, Sutherland DER, Najarian JS (1990) Effects of pancreatic transplantation on diabetic neuropathy. N Engl J Med 322: 1031-1037

Landgraf $R$, Landgraf-Leurs MMC, Burg D, Kampik A, Castro LA, Abendroth A, Illner WD, Land W (1986) Long-term follow-up of segmental pancreas transplantation in type 1 diabetics. Transpl Proc XVIII; 5: 1118-1124

Mitz M, Di Benedetto M, Klingbeil GE, Melvin JL, Pliering W (1984) Neuropathy in end-stage renal disease secondary to primary renal disease and diabetes. Arch Physiol Med Rehabil 65: 235-238

Nielsen K (1974) The peripheral nerve function peripheral in chronic renal failure. Recovery after renal transplantation. Electrophysiological aspects (sensory and motor nerve conduction). Acta Med Scand 195: 171-180

Pozza G, Traeger J, Secchi A (1991) Pancreas transplantation: whole organ and segmental. In: Alberti KGMM, DeFronzo R, Zimmet $P$ (eds) The international textbook of diabetes mellitus. Wiley Medical Publications, London

Secchi A, Martinenghi S, Galardi G, Comi G, Canal N, Pozza G (1990) Effects of pancreatic transplantation on diabetic polyneuropathy. Transpl Proc 23: 1

Service FJ, Rizza RA, Daube JR, O'Brien PC, Dyck PJ (1985) Near normoglycaemia improved nerve conduction and vibration sensation in diabetic neuropathy. Diabetologia 28:722-727 
G. Comi et al.: Follow-up of diabetic neuropathy after kidney and pancreas transplantation

Solders G, Wilczek H, Gunnarsson R, Tyden G, Persson A, Groth CG (1987) Effects of combined pancreatic and renal transplantation on diabetic neuropathy: a two-year follow-up study. Lancet 11: 1232-1235

Thomas PK (1990) The pathogenesis of diabetic neuropathy: current problem and prospects. In: Diabetic Neuropathy, J Ward and Y Goto (eds), John Wiley and Sons: 3-16

Van Der Vliet JA, Navarro X, Kennedy WR, Goetz FC, Najarian JS, Sutherlan DER (1988) The effects of pancreas transplantation on diabetic polyneuropathy. Transplantation $45 ; 2: 368-370$

Van Der Vliet JA, Navarro X, Kennedy WR, Goetz FC, Barbosa JJ, Sutherland DER, Najarian JS (1988) Long-term follow-up of polyneuropathy in diabetic kidney transplant recipients. Diabetes 37: 1247-1252

Ward JD, Barnes CG, Fisher DJ, Jessop JD (1971 Improvement in nerve conduction following treatment in newly diagnosticated diabetes.Lancet i: $428-430$

Prof. G. Comi

Department of Neurology

San Raffaele Institute

via Olgettina 60

20132 Milan

Italy 